\title{
Associations between Pro- and Anti-Inflammatory Gastro-Intestinal Microbiota, Diet, and Cognitive Functioning in Dutch Healthy Older Adults: The NU-AGE Study
}

\author{
Annick P. M. van Soest ${ }^{1, *,+}\left(\mathbb{D}\right.$, Gerben D. A. Hermes ${ }^{2,+}{ }^{\oplus}$, Agnes A. M. Berendsen ${ }^{1}(\mathbb{C}$, \\ Ondine van de Rest ${ }^{1}\left(\mathbb{D}\right.$, Erwin G. Zoetendal ${ }^{2}$, Susana Fuentes ${ }^{2,3}{ }^{(}$, Aurelia Santoro ${ }^{4,5}$, \\ Claudio Franceschi ${ }^{4,6}$, Lisette C. P. G. M. de Groot ${ }^{1, \ddagger(\mathbb{D})}$ and Willem M. de Vos ${ }^{2,7, \ddagger(\mathbb{D})}$ \\ 1 Division of Human Nutrition and Health, Wageningen University \& Research, \\ 6708WE Wageningen, The Netherlands; agnes.berendsen@wur.nl (A.A.M.B.); \\ ondine.vanderest@wur.nl (O.v.d.R.); lisette.degroot@wur.nl (L.C.P.G.M.d.G.) \\ 2 Laboratory of Microbiology, Wageningen University \& Research, 6708WE Wageningen, The Netherlands; \\ gerben.hermes@wur.nl (G.D.A.H.); erwin.zoetendal@wur.nl (E.G.Z.); susana.fuentes@rivm.nl (S.F.); \\ willem.devos@wur.nl (W.M.d.V.) \\ 3 Center for Infectious Disease Control, National Institute for Public Health and the Environment, \\ 3721MA Bilthoven, The Netherlands \\ 4 Department of Experimental, Diagnostic and Specialty Medicine, University of Bologna, 40126 Bologna, Italy; \\ aurelia.santoro@unibo.it (A.S.); claudio.franceschi@unibo.it (C.F.) \\ 5 AlmaMater Research Institute on Global Challenges and Climate Change (Alma Climate), University of Bologna, \\ 40126 Bologna, Italy \\ 6 Department of Applied Mathematics, Institute of Information Technology, Mathematics and Mechanics (ITMM), \\ Lobachevsky State University of Nizhny Novgorod-National Research University (UNN), \\ 603950 Nizhny Novgorod, Russia \\ 7 Human Microbiome Research Program, Faculty of Medicine, University of Helsinki, 00014 Helsinki, Finland \\ * Correspondence: annick.vansoest@wur.nl \\ + These authors contributed equally to this work. \\ $\ddagger \quad$ These authors contributed equally to this work.
}

Received: 30 September 2020; Accepted: 5 November 2020; Published: 12 November 2020

\begin{abstract}
Dietary modulation of the gastro-intestinal microbiota is a potential target in improving healthy ageing and age-related functional outcomes, including cognitive decline. We explored the association between diet, gastro-intestinal microbiota and cognition in Dutch healthy older adults of the 'New dietary strategies addressing the specific needs of the elderly population for healthy aging in Europe' (NU-AGE) study. The microbiota profile of 452 fecal samples from 226 subjects was determined using a $16 \mathrm{~S}$ ribosomal RNA gene-targeted microarray. Dietary intake was assessed by 7-day food records. Cognitive functioning was measured with an extensive cognitive test battery. We observed a dietary and microbial pro- to anti-inflammatory gradient associated with diets richer in animal- or plant-based foods. Fresh fruits, nuts, seeds and peanuts, red and processed meat and grain products were most strongly associated to microbiota composition. Plant-rich diets containing fresh fruits, nuts, seeds and peanuts were positively correlated with alpha-diversity, various taxa from the Bacteroidetes phylum and anti-inflammatory species, including those related to Faecalibacterium prausnitzii and Eubacterium rectale and E. biforme. Animal product-rich diets associated with pro-inflammatory species, including those related to Ruminococcus gnavus and Collinsella spp.. Cognition was neither associated with microbiota composition nor alpha-diversity. In conclusion, diets richer in animal- and plant-based foods were related to a pro- and anti-inflammatory microbial profile, while cognition was associated with neither.
\end{abstract}


Keywords: gut microbiota; dietary intake; cognitive decline; elderly; healthy ageing; inflammation

\section{Introduction}

The ageing population is growing rapidly. Worldwide, the number of people aged 65 years or over is currently estimated at 703 million. Due to a steep rise in life expectancy, this number is expected to double to 1.5 billion in 2050 [1]. Unfortunately, as the longer lifespan is not accompanied by improvements of health outcomes [2], the increase in life expectancy poses serious challenges to the health care system, economy and society [3]. Therefore, there is an urgent need for strategies to improve healthy ageing.

The gastro-intestinal (GI) microbiota has been implicated as a potential target to enhance healthy ageing [4]. Ageing is accompanied by several physiological and lifestyle changes, including altered GI tract function, elevated inflammation levels and dietary changes, that affect the GI microbiota $[5,6]$. Compared to younger adults, the GI microbiota in older adults has been shown to exhibit larger inter-individual and temporal variation. It was also strongly correlated to diet, which was linked to residence location in the community $[7,8]$. Despite the larger variation, several universal changes in the GI microbiota that occur with ageing have been identified. Generally, the relative abundance of Bifidobacterium spp. was found to be lower in older adults with concomitant higher levels of Enterobacteriaceae and other pathobionts [5,6].

Changes in GI microbiota composition may influence age-related functional outcomes, such as cognitive decline. In the past decade, the link between altered GI microbiota composition and cognition has been demonstrated in various rodent models, including germ-free animals and several microbiota modulation strategies, such as antibiotics, pre- or pro-biotics, and fecal microbiota transplants [9]. For example, rodents with disrupted GI microbial homeostasis, due to infection or treatment with antibiotics, perform worse on cognitive tests compared to animals with an undisturbed GI microbiota. Restoring this homeostasis by administration of probiotics or via fecal microbiota transplantation positively influenced cognitive performance of rodents [9]. In humans, administration of Bifidobacterium and Lactobacillus species for 12 weeks has shown to positively affect cognitive functioning in older adults $[10,11]$, providing preliminary evidence for a relation between GI microbiota and cognition in humans, thus proposing the GI microbiota as a target to prevent or delay age-related cognitive decline.

Modification of diet has been suggested as a strategy to both maintain cognition and GI homeostasis. There is special interest in the Mediterranean diet (MedDiet), which is characterized by a high intake of vegetables, fruits, legumes and olive oil and moderate to low intake of animal-based food products [12]. Greater adherence to the MedDiet has been associated to slower rates of age-related cognitive decline $[13,14]$ and beneficial changes in GI microbiota composition $[15,16]$.

To our knowledge, to date only one human study has investigated the relation between diet, cognition and GI microbiota. Data from all European partners of the 'New dietary strategies addressing the specific needs of the elderly population for healthy aging in Europe' (NU-AGE) study, a one-year Mediterranean-like dietary intervention, showed that individuals with better adherence to this diet had higher relative abundances of several microbial groups, including Faecalibacterium prausnitzii, Anaerostipes and Roseburia [16], which have previously been linked to beneficial health effects. For instance, these species exhibit anti-inflammatory properties, are able to produce the short chain fatty acid (SCFA) butyrate and have been inversely associated with diabetes mellitus type 2 and colorectal cancer [17-19]. In turn, higher relative abundances of these beneficial species were weakly, but positively, associated with cognitive function measured by BabCock memory and constructional praxis performance [16].

These results provide preliminary evidence for the potential of the MedDiet to prevent age-related cognitive decline by modulating GI microbiota. However, it remains unclear which specific food groups of the MedDiet are responsible for the potentially beneficial effects on cognition and GI microbiota 
composition. Moreover, in the previous study, cognitive function was measured by means of single tests [16], whereas the assessment of multiple cognitive tests representing all cognitive domains and combining these tests into composite cognitive scores is a more robust measure of cognitive functioning [20]. Therefore, the current study aims to explore the relation between diet, GI microbiota composition and cognitive function in healthy older adults (65-79 years).

\section{Materials and Methods}

\subsection{Study Design and Participants}

We used data from the Dutch cohort of the NU-AGE study, a parallel randomized one-year study investigating the effect of a dietary intervention on inflammation in European older adults [21]. Cognitive functioning and microbiota composition were determined as secondary outcomes. Information on participants, recruitment and the dietary intervention has previously been described in detail [22,23]. In short, 252 healthy Dutch older adults aged 65-79 years were randomized to the intervention or control group. Participants in the intervention group received individually tailored dietary advice to follow a Mediterranean-like diet. The control group received no specific dietary advice except for a leaflet describing the national guidelines for a healthy diet. Analyses showed that the intervention did not affect GI microbiota. Therefore, the current study has a cross-sectional design, in which data from both pre and post intervention are combined. Participants were non-frail (fried frailty $\leq 1$ [24]) and free of major diseases including cancer, dementia, diabetes mellitus type I and II and organ failure, and did not use antibiotics in the three months prior to inclusion. Dietary intake, GI microbiota composition and cognitive functioning were assessed at baseline and post intervention. Data from 26 participants were excluded due to missing GI microbiota assessments at either pre or post intervention. The NU-AGE study has been registered at clinicaltrials.gov (identifier: NCT01754012). This study was conducted according to the Declaration of Helsinki and written informed consent was obtained from all participants. The study protocol was approved by the Medical Ethics Committee of Wageningen University and Research (ABR 37818.081.11).

\subsection{Dietary Assessment}

At baseline and post intervention, dietary intake was assessed by a 7-day food record. Participants were instructed to record all consumed foods and their amounts based on household measures. All food records were reviewed by a trained research dietician during an interview. Consumed food products were coded according to standardized coding procedures. Nutrient intake data was calculated by use of the Dutch food composition table (NEVO 2011). Consumed food products with similar composition were grouped into food groups according to the EPIC-Soft Classification [25] with some local modifications. Additional groups were created for ready-to-eat meals and savory bread spreads as products in these groups were not included in the current EPIC-Soft list. Separate groups were created for low fat, and salt and sugar options within the dairy food groups based on the Dutch dietary guidelines [26]. Products containing artificial sweeteners were placed in a separate group as sweeteners have been shown to influence GI microbiota composition [27]. In addition, a separate group was made for legume-based ready to eat soups due to the relatively high fiber content. Finally, the food group meat was divided into red meat, processed meat, poultry and meat replacers instead of groups based on animal origin to limit the number of food groups.

\subsection{Microbiota Composition Profiling}

At baseline and post intervention, participants were instructed to collect a fecal sample at home with the help of a stool collection kit and store them immediately at $-20^{\circ} \mathrm{C}$. Samples were transported in coolers and then stored at $-20^{\circ} \mathrm{C}$ and later at $-80{ }^{\circ} \mathrm{C}$ before being processed. DNA extraction from fecal samples has been described in detail elsewhere [28]. In brief, DNA was extracted using a combination of column purification and repeated-bead-beating. Purity and concentration of DNA 
were assessed with a Nanodrop 1000 spectrophotometer (Thermo Fisher Scientific, Wilmington, USA). The composition analysis was then performed utilizing a previously benchmarked custom made, phylogenetic microarray, the human intestinal tract chip (HITChip) [29,30]. The HITChip contains a duplicated set of 3631 probes, which target the V1 and V6 hypervariable regions of the 16S rRNA gene of 1140 intestinal bacterial phylotypes. After extraction of DNA, the full-length 16S rRNA gene was amplified by PCR using primers T7prom-Bact-27-for and Uni-1492-rev [30]. This was followed by in vitro transcription and labelling of the resulting RNA with $\mathrm{Cy} 3 / \mathrm{Cy} 5$ before hybridization to the array. The signal intensity data from the microarray hybridizations were collected from the Agilent G2505C scanner (Agilent Technologies) using Agilent Feature Extraction software, version 10.7.3.1 and pre-processed using an in-house MySQL database and custom R scripts. Each scanner channel from the array was separately spatially normalized using polynomial regression, followed by outlier detection and filtering in each set of probes with a $\chi 2$ test. Each sample was hybridized at least twice to ensure reproducibility. Duplicate hybridizations with a Pearson correlation $<0.98$ were not considered for further analysis. Microbiota profiles were summarized to genus-like 16S rRNA gene sequence groups with a sequence similarity $>90 \%$ referred to as species and relatives ('et rel.'). Measurements of probes that belong to the same phylotype were normalized with robust probabilistic averaging [31,32]. Log10-transformed hybridization signals were used as a proxy for bacterial abundance.

\subsection{Cognitive Functioning}

Cognitive functioning was assessed at baseline and post intervention with an extensive battery of cognitive tests which were administered by trained research assistants. The battery included cognitive tests from the consortium to establish a registry for Alzheimer's disease (CERAD) test battery [33] plus five additional tests.

In the verbal fluency category test [34], participants were asked to name as many animals as possible within $60 \mathrm{~s}$. The number of uniquely named animals was recorded. Participants were presented with four figures in the constructional praxis test [35], and asked to copy these figures on blank paper immediately after presentation (subtest immediate) and after a few minutes (subtest recall). Scoring was based on the number of correct responses. In the word list memory test [33], participants were visually presented with ten random words. The number of correctly recalled words directly after presentation in three trials (subtest immediate) and after five minutes in one trial (subtest delayed) was recorded. Finally, the participant was asked to identify the ten words from a verbally presented list of twenty words (subtest recognition). Next, participants were read a brief story in the Babcock story recall test [36] and asked to retell the story immediately (subtest immediate) and after 20 min (subtest delayed). Scoring was based on the correctly recalled parts of the story. In the trail making test [37], participants were instructed to connect 25 numbers in chronological order (Part A) and to connect numbers and letters in chronological and alphabetical order alternately (Part B). Time to complete each task was recorded. In the number cancellation test [38], participants were presented with a list of random numbers. The number of correctly crossed out $4 \mathrm{~s}$ in $30 \mathrm{~s}$ was documented. In the pattern comparison test [39], participants were asked to indicate if two patterns were similar or different. Scoring was based on the number of correct responses.

Scores for each of the cognitive tests were converted into Z-scores with baseline mean and standard deviation of the whole population. The Z-score for the trail making test was reversed as lower scores represent better cognitive functioning. The individual Z-scores for the cognitive tests were clustered into four cognitive domains:

$$
\begin{gathered}
\text { Episodic memory }=\left(z \text { WordList }_{\text {immediate }}+z \text { WordList } \text { delayed }+z\right. \text { WordList } \\
\text { recognition }
\end{gathered}
$$

Executive functioning $=\left(z\right.$ VerbalFluency +- zTrailMakingTest $\left._{\mathrm{B} / \mathrm{A}}\right) / 2$ 
Information processing speed $=\left(-z\right.$ TrailMakingTest $_{\mathrm{A}}+z$ NumberCancellation $_{+}$

$$
\text { zPatternComparison) } / 3
$$

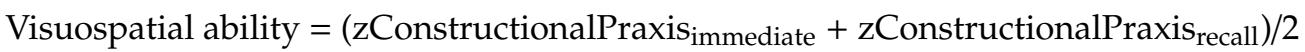

\subsection{Assessment of Phenotypical Characteristics}

Body weight and height were measured by trained research assistants. Weight was determined while wearing light clothing to the nearest $0.1 \mathrm{~kg}$ using a calibrated scale. Height was measured using a stadiometer to the nearest $0.1 \mathrm{~cm}$. Body mass index (BMI) was calculated as weight/height ${ }^{2}$. Data on age, sex, education (number of years) and smoking status (never, former or current) were collected using questionnaires. Frailty status (non-frail/pre-frail) [24] and mini-mental state examination (MMSE) [40] were assessed by trained research assistants following standardized procedures. MMSE scores from 24 to 30 are considered within the normal range [40]. Physical activity was measured using the physical activity scale for elderly (PASE). For individuals aged 70 to 75 , average values for PASE are 89.1 for women and 102.4 for men [41].

\subsection{Statistical Analyses}

All microbiota analyses were performed in $R$ version 3.4.0 [42]. Redundancy analysis (RDA) was performed to determine the multivariate effects of the explanatory variables on microbiota composition using the rda function from the vegan package [43]. RDA is a technique summarizing the linear relationships between a set of variables i.e., GI microbiota composition explained by a set of explanatory variables, i.e., dietary and host variables. The effect of an explanatory variable is defined as $\mathrm{R}^{2}$, which is the percentage of variation explained from the total amount of microbiota variation. All numerical environmental variables (food groups, nutrients, phenotype and cognition) were normalized to ensure that the input variables had similar scales before performing the RDA. We first determined the simple effects of all explanatory variables on microbiota composition to help understand what was driving the interactions. Because the dietary intervention had no significant effect on microbiota composition, we performed a cross-sectional analysis with both pre- and post-intervention samples to increase power. To determine which set of food groups resulted in the most parsimonious model (i.e., explaining microbiota variation), we performed forward and reverse automatic stepwise model selection for constrained ordination methods using permutation tests with the ordistep function from the vegan package, which bases the term choice on Akaike's information criterion and $p$-value. This ordination configuration was used to test which other explanatory variables (nutrients, phenotype and cognition) significantly correlated with microbiota composition by post-hoc fitting these as vectors using the envfit function from vegan. Significance was set at $p<0.05$. Richness, inverse Simpson and Shannon diversity were calculated to define microbial alpha-diversity using the microbiome package [44]. In ecology, alpha-diversity is defined as the species diversity within a sample. We used to commonly applied methods to determine diversity, viz Shannon diversity and inverse Simpson diversity. Diversity of the microbiota was based on non-logarithmic oligo-level signals and probes were counted in each sample to measure richness, by using an $80 \%$ quantile threshold for detection. To correlate microbial alpha-diversity with the significant explanatory variables we used Pearson correlations and visualized these using heatmaps with the psych package [45]. $p$-values were corrected for multiple testing using the Benjamini-Hochberg procedure [46] and $q<0.05$ was considered significant.

\section{Results}

\subsection{Participant Characteristics}

At baseline, the mean age of participants was $70.9 \pm 4.1$ years and $44.4 \%$ of the study population was male (Table 1). The average body mass index (BMI) at baseline was $25.9 \pm 3.6 \mathrm{~kg} / \mathrm{m}^{2}$ and mean score on the mini-mental state examination (MMSE) was $27.7 \pm 1.8$ points, indicating that our study 
population was cognitively healthy. The mean PASE score was $137 \pm 54$, indicating that the physical activity level was slightly higher than normal compared to a study population with similar age [41].

Table 1. Baseline characteristics of 226 healthy Dutch older adults.

\begin{tabular}{cc}
\hline Characteristic & $n=\mathbf{2 2 6}$ \\
\hline Age, years & $70.9 \pm 4.1$ \\
Sex, male $n(\%)$ & $100(44.2 \%)$ \\
Education, years & $12.3 \pm 3.7$ \\
BMI, kg/m ${ }^{2}$ & $25.9 \pm 3.6$ \\
Smoking status, $n(\%)$ & \\
Never & $117(51.8 \%)$ \\
Former & $103(45.6 \%)$ \\
Current & $6(2.7 \%)$ \\
MMSE (score 0-30) & $27.7 \pm 1.8$ \\
Physical activity (PASE score) & $137 \pm 54$ \\
Frailty, $n(\%)$ & \\
Non-frail & $178(78.8 \%)$ \\
Pre-frail & $48(21.2 \%)$ \\
\hline
\end{tabular}

Abbreviations: BMI: body mass index; MMSE: mini mental state examination; PASE: physical activity scale for the elderly. Data are presented as mean \pm SD or number $(\%)$.

\subsection{Variables Affecting GI Microbiota Composition}

To determine how the different environmental variables impact the microbiota, we first calculated their simple effects (i.e., the effect of the environmental variable on the microbiota without any other covariates). As previously described in the methods, the dietary intervention had no significant effect on microbiota composition $\left(p=1.0, \mathrm{R}^{2}=0.08 \%\right.$ ). A total of 41 variables, existing of phenotypical characteristics, food groups and nutrients, significantly correlated to GI microbiota composition as shown in Figure 1. The largest proportion of GI microbiota variation was explained by individuals $\left(\mathrm{R}^{2}=40.0 \%\right)$ (Supplementary Figure $\left.\mathrm{S} 1\right)$. The phenotypical characteristics BMI $\left(\mathrm{R}^{2}=0.73 \%\right)$ and sex $\left(\mathrm{R}^{2}=0.22 \%\right)$ were both correlated with microbiota composition. BMI explained the largest proportion of microbiota variation out of all microbiota covariates. With respect to the dietary variables, 29 nutrients and 10 food groups were significantly correlated with GI microbiota composition. Concerning the food groups, fresh fruits explained the highest proportion of variation in GI microbiota composition $\left(\mathrm{R}^{2}=0.51 \%\right)$. Further zooming in on the fresh fruits showed that berries and grapes were the fruits most contributing to this observation. Other significant food groups were nuts, seeds and peanuts $\left(R^{2}=0.45 \%\right)$, grain products $\left(R^{2}=0.39 \%\right)$ and both processed and red meat $\left(R^{2}=0.36 \%\right.$ and $R^{2}=0.25 \%$ respectively). Among the nutrients, total protein $\left(\mathrm{R}^{2}=0.46 \%\right)$ and protein from animal $\left(\mathrm{R}^{2}=0.62 \%\right)$ and plant $\left(\mathrm{R}^{2}=0.42 \%\right)$ sources explained the largest proportion of variation. In addition, various forms of carbohydrates, water-soluble vitamins, minerals and omega-3 fatty acids were significantly associated to GI microbiota composition, while other fatty acids and fat-soluble vitamins did not. None of the cognitive functioning domains was significantly correlated with GI microbiota composition.

To visualize the relations between dietary factors and phenotypical characteristics with microbiota composition, their conditional effects (the impact on the microbiota with the effect of other variables in the model) were calculated and plotted in two RDA bi-plots (Figure 2). We observed a gradient of participants with higher intakes of plant-based foods and participants consuming higher amounts of animal-based foods. Higher intakes of these animal-based foods, animal protein, cholesterol, vitamin B12, low fat cheese, and red and processed meat, were correlated with a higher BMI. The participants with lower intake of animal-based foods and higher intake of plant-based foods could be further divided into two groups; those consuming higher amounts of fresh fruits, nuts, seeds and peanuts and vitamin C, and those with higher intakes of grain products and digestible carbohydrates. 

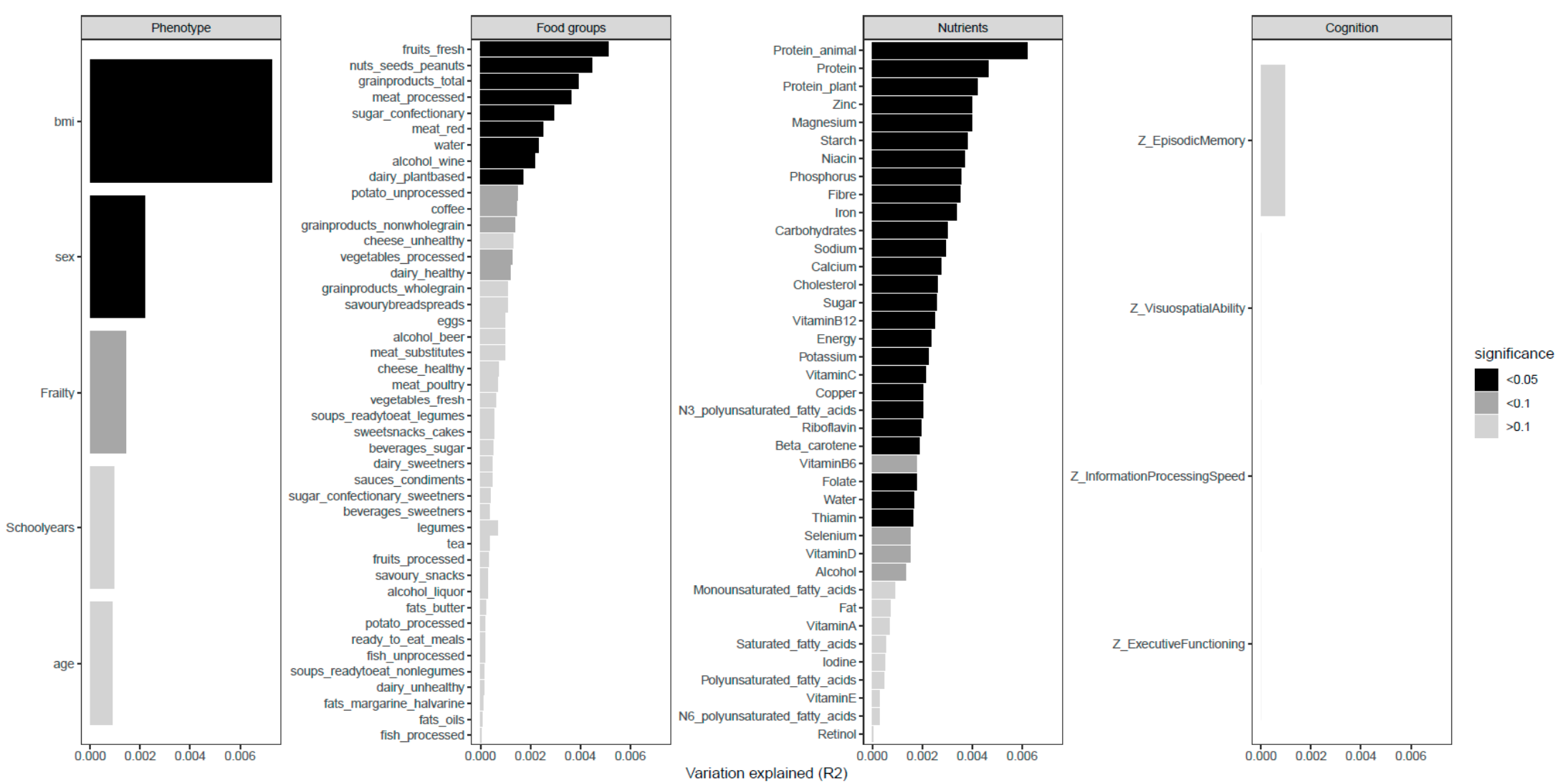

Figure 1. Microbiota covariates. Impact of all measured variables on microbiota composition defined as percentage variation explained ( $\left.\mathrm{R}^{2}\right)$ out of all the total microbiota variation. A higher $\mathrm{R}^{2}$ implies a stronger effect size. 

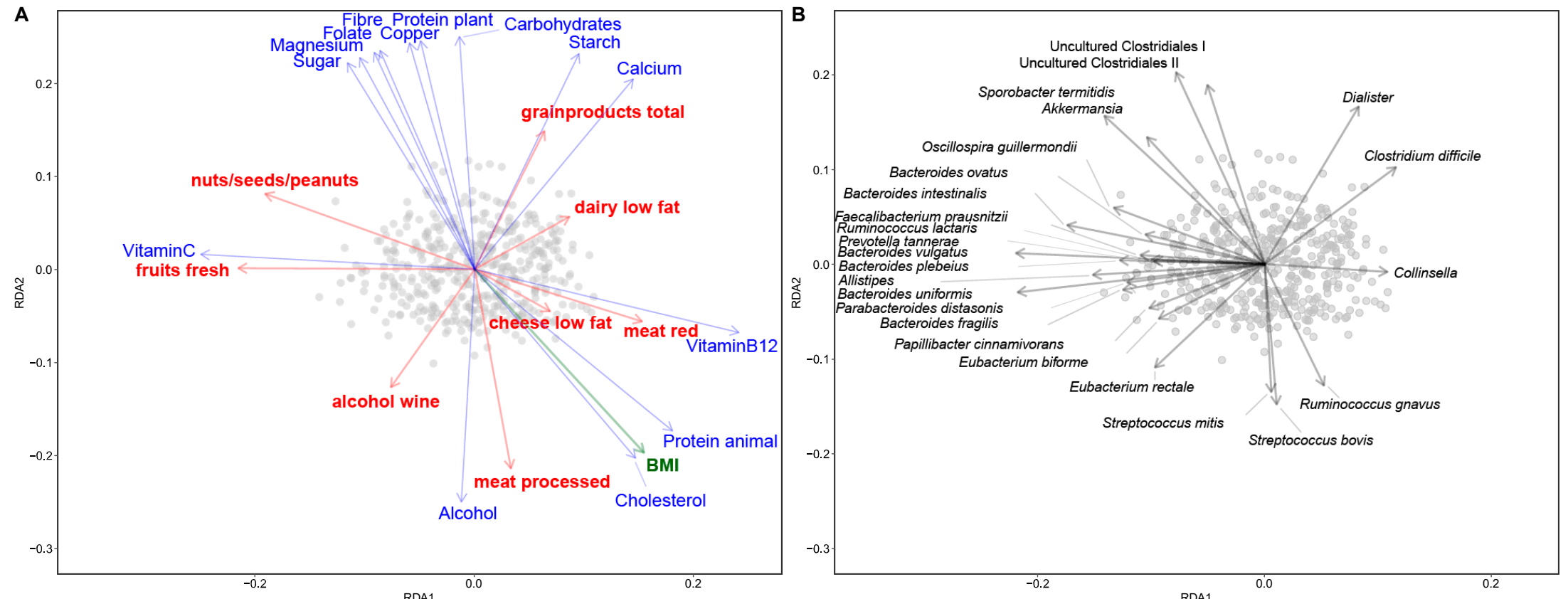

Figure 2. Association of microbiota with food groups, nutrients and BMI. Samples are plotted as grey circles. (A) Redundancy analysis (RDA) bi-plot of microbiota with explanatory variables; food groups (red), nutrients (blue) and phenotypical characteristics (green). (B) RDA bi-plot of samples with the associated microbial taxa (indicated as genera or species-level groups) The direction of the arrows depicts the abundance of microbial taxa. Length of the arrows is a measure of fit. The variable arrows approximate the correlation between species and explanatory variables. Samples near the coordinate origin (zero point) suggest near zero correlation. The further a sample falls in the direction indicated by the arrow, the higher the correlation. 
Consumption of animal-based foods and BMI was positively associated with species related to Ruminococcus gnavus, Streptococcus spp. (S. mitis and bovis) and Collinsella. Conversely, animal-based foods were inversely associated with Akkermansia muciniphila, uncultured Clostridiales I and II and species related to Sporobacter termitidis. Consumption of fresh fruits, its associated nutrient vitamin $\mathrm{C}$, and nuts, seeds and peanuts were associated with several genera from the Bacteroidetes phylum, including Bacteroides spp., Parabacteroides, Alistipes and Prevotella, and Firmicutes such as species related to Faecalibacterium prausnitzii, Oscillospira guillermondii and Eubacterium rectale and E. biforme. Grain products and carbohydrates were positively associated with Dialister and species related to Clostridium difficile (recently renamed to Clostridioides difficile). Although this group is named after C. difficile, the observed differences do likely not relate to this potential pathogen but probes targeting C. bifermentans, C. bartlettii and C. glycolicum.

\subsection{Variables Associated with Microbial Alpha-Diversity}

The relations between the significant variables in the RDA (phenotypical characteristics, nutrients, food groups) and indices that contribute to microbial alpha-diversity were calculated and visualized in Figure 3A. BMI was negatively correlated with alpha-diversity. With respect to the food groups, only fresh fruits and nuts, seeds and peanuts were positively correlated with alpha-diversity, with correlation coefficients ranging from 0.1 to 0.17 . Among the fresh fruits, alpha diversity positively correlated with berries and grapes, citrus fruits and stone fruits in Supplementary Table S1. Nutrients that were positively correlated to alpha-diversity included vitamin C, various minerals, forms of carbohydrate and plant protein, with correlation coefficients between 0.09 and 0.14 . None of the nutrients was negatively associated with alpha-diversity.

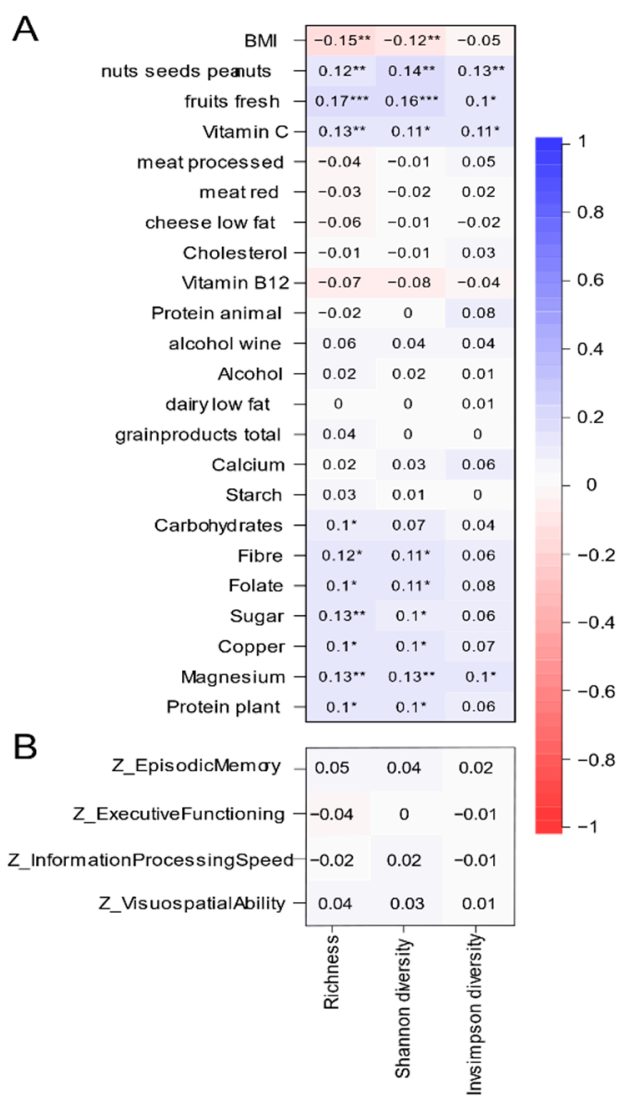

Figure 3. Correlation of alpha-diversity with microbiota covariates (A) and cognition variables (B). Pearson correlation of significant microbiota covariates were calculated. $p$ values are corrected for multiple testing using the Benjamini-Hochberg procedure. ${ }^{* *} \mathrm{q}<0.001,{ }^{* *} \mathrm{q}<0.01{ }^{*} \mathrm{q}<0.05$. 
With correlation coefficients ranging from -0.04 to 0.05 , none of the cognitive domains was significantly correlated to any of the diversity indices (Figure 3B).

\section{Discussions}

By exploring associations between diet, GI microbiota and cognition in healthy Dutch older adults using food groups as the primary input, we showed that fresh fruits, nuts, seeds and peanuts, red and processed meat, grain products, low fat dairy and cheese and wine are important dietary factors in GI microbiota composition. Of these food groups, fresh fruits (berries and grapes in particular), and nuts, seeds and peanuts positively correlated with alpha-diversity. Overall, fresh fruits and nut seeds and peanuts correlated with various taxa from the Bacteroidetes phylum and species related to Faecalibacerium prausnitzii, grain products correlated with Dialister, while higher intake of animal-based foods was associated with a higher abundance of Collinsella and Streptococcus spp. as well as species related to Ruminococcus gnavus. Cognitive functioning was neither associated with GI microbiota composition nor alpha-diversity.

Our study is the first to investigate which food groups are related to whole GI microbiota composition and alpha-diversity in older adults. In younger adults, several studies have investigated this association before. In a large cross-sectional study with GI microbiota data from 1135 Dutch adults, 78 dietary factors, including fruit, frequency of nut consumption, red and processed meat and protein, were important dietary factors in explaining GI microbiota variation [47]. The associations of fruit and meat with GI microbiota composition were confirmed in a large cross-sectional Belgian study with adults $(n=1106)$ [48] and the French Milieu Intérieur study $(n=862)$ [49] showed that fruit influenced the GI microbiota. With respect to alpha-diversity, our finding that individuals with higher intakes of fresh fruit and nuts had a more diverse GI microbiota was confirmed by the studies of Dutch and French adults $[47,49]$ and the association between nuts, seeds and peanuts and alpha-diversity was also observed in Dutch adults [47].

Despite the fact that the dietary intervention did not have a significant impact on the GI microbiota in our cohort, we could clearly identify associations between dietary variables and microbiota composition. We observed a gradient between participants consuming a diet richer in foods from animal origin and a diet richer in foods from plant origin, from now on referred to as animal- and plant-rich diets. The animal-rich diet was characterized by higher intakes of processed and red meat, low fat cheese and dairy, vitamin B12 and cholesterol. The plant-rich diet was higher in vitamin C, fresh fruits and nuts, seeds and peanuts. In addition to the classification based on origin of the food products and nutrients, these diets can also be classified as pro- and anti-inflammatory according to the dietary inflammatory index, in which various dietary factors have been scored based on their inflammatory potential [50]. Vitamin B12 and cholesterol, both associated with the animal-rich diet, were considered pro-inflammatory. With respect to the plant-rich diet, nutrients present in fresh fruits (vitamin C, flavonoids, fiber) and nuts, seeds and peanuts (polyphenols, omega-3 fatty acids, fiber) were all classified as anti-inflammatory.

Interestingly, classification of the GI microbiota based on inflammatory potential showed a similar pattern. The consumption of the pro-inflammatory diet rich in animal foods positively correlated with Collinsella and Streptococcus spp. as well as species related to R. gnavus. Overall, these bacteria have been classified as pro-inflammatory. Increased abundance of Collinsella has been observed in several inflammatory diseases, including type 2 diabetes mellitus [51,52], atherosclerosis [53] and rheumatoid arthritis [54]. Even though Streptococcus is a normal inhabitant of the upper GI tract, increased abundance in the colon has been associated with pro-inflammatory nutrients of animal origin [15]. Finally, higher abundance of R. gnavus has been linked to several inflammatory diseases as well, such as spondyloarthritis [55], eczema in infants [56] and inflammatory bowel disease, especially during active disease episodes [57]. In addition to the connection with inflammatory diseases, it has recently been shown that $R$. gnavus synthesizes an inflammatory polysaccharide that induces secretion of the inflammatory cytokine tumor necrosis factor-alpha by dendritic cells [58]. 
The anti-inflammatory plant-rich diet was associated with species related to F. prausnitzii, E. rectale and E. biforme. These species can be classified as anti-inflammatory due to their ability to produce butyrate. Butyrate has been shown to exhibit anti-inflammatory effects through their regulation of leukocyte function via inhibition of histone deacetylase and activation of G-protein coupled receptors [59]. These anti-inflammatory effects of butyrate have been demonstrated in vivo, in both animal models [60] and human clinical trials [61]. F. prausnitzii specifically has been shown to exhibit anti-inflammatory effects in vitro and in vivo. In peripheral blood mononuclear cells, F. prausnitzii led to higher levels of the anti-inflammatory cytokine IL-10 and lower production of the pro-inflammatory cytokines IL-12 and IFN- $\gamma$. In a mouse model with induced acute colitis, administration of living F. prausnitzii decreased colitis [62]. Moreover, in humans lower abundance of these species has been observed in several inflammatory diseases. A meta-analysis in inflammatory bowel disease patients showed that patients suffering from an active disease episode had lower abundance of $F$. prausnitzii compared to patients in remission [63] and E. rectale were reduced in Crohn's disease patients compared to healthy controls [64]. The plant-rich diet also positively correlated to the mucin degrading species A. muciniphila. Similarly, lower abundance of $A$. muciniphila has been observed in inflammatory conditions including obesity and type 2 diabetes [65-67]. Moreover, a recent human intervention trial showed that daily administration of $A$. muciniphila cells for three months increased barrier function, by decreasing the levels of pro-inflammatory lipopolysaccharides in prediabetic human subjects [68]. Overall, the links between these bacteria and inflammatory diseases and compounds, indicate that the consumption of an animal-rich diet might correlate with a more pro-inflammatory GI microbiota profile, while the plant-rich diet correlates to a more anti-inflammatory GI microbiota profile.

Moreover, several species associated to the plant-rich diet, including F. prausnitzii and E. rectale, have been previously associated with a high adherence to the MedDiet in various European countries [16]. This might imply that certain food groups that were part of the plant-rich diet, i.e., nuts, seeds and peanuts and fresh fruits, are important dietary factors in the MedDiet with respect to GI microbiota modulation. The beneficial associations of these food groups could be due to the fiber present in fruits and nuts. Fermentation of fibers in the gut leads to the production of SCFA, which have beneficial effects on health as previously discussed [69]. An additional factor underlying the beneficial associations might be the presence of polyphenols in fruit and nuts. These plant metabolites are poorly absorbed in the small intestine and reach the colon where they can interact with microbiota. Polyphenols have been shown to have prebiotic-like effects. Various types of polyphenols enhanced growth of lactobacilli and bifidobacteria as well as Akkermansia, in both in vitro and in vivo (animal and human) studies [70,71].

In addition to the association between the plant-rich diet and the anti-inflammatory species, the diet rich in plant foods also positively correlated with several genera from the Bacteroidetes phylum such as Parabacteroides, Alistipes, and mostly Bacteroides and Prevotella spp.. Members of the latter two maintain a complex and generally beneficial relationship with the host. Bacteroidetes are abundantly present in the human gut and many genera within this phylum respond to changes in diet. Generally, diets rich in fiber are linked with increased abundance of Prevotella spp. [72], while higher abundance of Bacteroides spp. is associated to diets rich in fat and protein from animal origin [73]. However, the latter group has also been linked to plant-based complex carbohydrates and inversely associated with dietary fat and protein [15], in line with our results. It is well known that microorganisms have context-dependent functions and a changing metabolism, depending on environmental conditions and the presence and function of other microbes. For instance, Bacteroides spp. contain a large repertoire of enzymes to break down complex plant carbohydrates [74], which likely underlies their association in the current study. However, several Bacteroides spp. are also bile resistant [75] and could thus be more prevalent in individuals consuming high fat diets with little complex carbohydrates. Additionally, different species or strains within the Bacteroides and Prevotella genera have been shown to be genetically diverse and associated with different dietary components, such as plant-based diets, while some are associated with animal-based nutrients $[76,77]$. Another factor in the ambiguity of the health 
associations of Bacteroides spp. is their status as a pathogen, as several species (notably B. fragilis) can cause significant pathology, including bacteremia and abscess formation in multiple body sites [75]. Similarly, several Prevotella spp. have been associated with chronic inflammatory conditions [78]. In contrast, Bacteroides spp. have also been linked to beneficial effects on health. This apparent duality was exemplified by the observation of a cohort specific positive or negative association with markers of insulin resistance in overweight insulin resistant males [79]. For example, Bacteroides spp. can contribute to the formation the SCFA propionate via the succinate pathway [80]. Propionate has been linked to several health benefits, including regulation of appetite and lipid synthesis in in vivo animal studies, and anti-colorectal cancer effects in in vitro models [81].

Specific food groups, such as berries and nuts, seeds and peanuts, were correlated with several anti-inflammatory microbial species. In addition, these food groups have been associated with slower rates of cognitive decline [82,83]. Although inflammation is a major mechanism underlying cognitive decline [84], we did not find associations between cognitive functioning and the GI microbiota composition or alpha-diversity. To our knowledge, the association between diet, gastro-intestinal microbiota and cognitive functioning in humans has only been investigated in a single other study [16]. Here, the authors showed that European individuals with high adherence to a Mediterranean-like diet had high relative abundance of several beneficial, anti-inflammatory, butyrate producing microbial groups, including Faecalibacterium prausnitzii, Anaerostipes and Roseburia. Increased relative abundance of these species was associated with improved cognitive function measured by single tests. Our approach augments this paper, but also differed in two aspects. First, we used diet as a combination of different food groups, while in the previous paper diet was only considered as adherence to the Mediterranean diet in general. Hence, it was not clear which specific food groups of the Mediterranean diet were responsible for the beneficial effect on cognition and gastro-intestinal microbiota composition. Second, we incorporated cognitive functioning outcomes using a robust measure of cognitive functioning by calculating mean scores per cognitive domain (composite cognitive scores). The previous research only considered scores of single cognitive tests. Aside from the use of a more robust measure of cognitive functioning, there are several other explanations for the apparent differing results with regard to the association of microbiota with cognitive function.

From animal studies, there is strong evidence for a relation between the gut and the brain, which has been shown with (germ-free) rodent studies, using microbiota modulating strategies such as antibiotics and fecal microbiota transplants [9]. However, there are many differences between rodents and humans, such as differences in GI tract anatomy and physiology and microbiota composition [85], severely limiting translation from rodents to humans. In addition, rodent models allow for more extreme interventions, have a very homogeneous genetic background and there is a high level of control over external factors, which allow for the demonstration of subtle effects. In contrast, we investigated cross-sectional relations in a healthy population of older adults in which diets and microbiota were relatively homogeneous. There were no extreme variations in intake of food components between participants and the dietary intervention that half of the participants underwent, resulted in small changes in dietary intake (e.g., increase of one slice of whole-wheat bread, one third of an apple, and half a serving spoon of vegetables extra per day) [23]. This may have limited the demonstration of associations between cognitive functioning and GI microbiota.

Moreover, our study population consisted of cognitively healthy older adults as shown by the mean MMSE score of 27.7 points out of 30, as scores from 24 to 30 are considered within the normal range [40]. Cognitively healthy indicates that these participants were no mild cognitive impairment or dementia patients. It is important to emphasize that cognitively healthy older individuals can benefit from the effects of diet on cognition. Cognitive health is not static, but rather a progressive phenomenon. The process of age-related cognitive decline starts from the late 20s and continuous throughout the lifespan [86]. The rate of decline can be influenced by several lifestyle factors, including nutrition. Previous research has already demonstrated that several dietary patterns can slow down cognitive decline with ageing. For example, this has been shown for the Mediterranean, Dietary Approaches 
to Stop Hypertension (DASH) and Mediterranean-DASH Intervention for Neurodegenerative Delay (MIND) diets [87].

Nevertheless, gastro-intestinal microbiota targeted interventions to slow down cognitive decline may be more effective in cognitively impaired individuals, i.e., mild cognitive impairment or Alzheimer's disease patients. Mild cognitive impairment and Alzheimer's disease patients have shown decreased microbial diversity and similar changes in GI microbiota compared to healthy older adults [88]. In line with this, the effectiveness of probiotic supplementation on cognition in humans likely depends on the degree of cognitive impairment. In human intervention studies, the effect of probiotic supplementation on cognitive functioning is mainly effective in cognitively impaired individuals (i.e., mild cognitive impairment or Alzheimer's disease patients), $[10,89,90]$ while the effectiveness in relatively healthy older adults has been inconsistent [11,91,92]. Similarly, the efficacy of other dietary interventions to slow down cognitive decline has been shown to be dependent on the extent of cognitive impairment as well [93]. Therefore, our study population might have been too healthy to demonstrate the link between cognition and GI microbiota. Indeed, changes in GI microbiota in older adults seem to be more strongly associated with health status rather than with chronological age [5,94].

The study population is an important limitation of this study. We did not demonstrate associations between cognitive functioning and GI microbiota, possibly due to relatively small differences in diet and microbiota between subjects and the high cognitive health status of our study population. Further research on the association between diet, GI microbiota and cognitive ageing in humans would benefit from focusing on cognitively impaired study populations and study populations that are more heterogeneous with respect to dietary intake.

\section{Conclusions}

This cross-sectional investigation into the association between diet, GI microbiota and cognition showed that the anti-inflammatory potential of a plant-rich diet high in fresh fruits and nuts, seeds and peanuts was linked to a GI microbiota profile with a higher anti-inflammatory potential. Conversely, a pro-inflammatory animal-rich diet was associated with a more pro-inflammatory GI microbiota profile. Despite the prominent role of inflammation in cognitive decline, we did not demonstrate associations between cognitive functioning and GI microbiota.

Supplementary Materials: The following are available online at http://www.mdpi.com/2072-6643/12/11/3471/s1, Figure S1: microbiota covariates. Impact of the individual and all measured variables and on microbiota composition defined as percentage variation explained (R2) out of the total microbiota variation. Table S1: Pearson correlation of alpha-diversity with fresh fruit categories.

Author Contributions: Conceptualization, L.C.P.G.M.d.G., W.M.d.V., A.S., C.F.; formal analysis, G.D.A.H., A.P.M.v.S.; investigation, A.A.M.B, S.F.; writing-original draft preparation, A.P.M.v.S., G.D.A.H.; writing-review and editing, A.P.M.v.S., G.D.A.H., A.A.M.B., O.v.d.R., E.G.Z., S.F., L.C.P.G.M.d.G., W.M.d.V.; supervision, O.v.d.R., L.C.P.G.M.d.G., E.G.Z.; funding acquisition, L.C.P.G.M.d.G., W.M.d.V., A.S., C.F. All authors have read and agreed to the published version of the manuscript.

Funding: The NU-AGE study was supported by the European Union's Seventh Framework Programme, grant number No. 266486 ('NU-AGE: new dietary strategies addressing the specific needs of the elderly population for healthy aging in Europe'). G.D.A.H. was supported by the project MASTER (Microbiome Applications for Sustainable food systems through Technologies and Enterprise) funded by the European Union's H2020 research and innovation program under grant agreement No. 818368. Microbiota analysis was funded by the 2008 Spinoza Award of the Netherlands Organization for Scientific Research to W.M.d.V.

Acknowledgments: The authors thank all study participants and all co-workers who were involved in the data collection of the NU-AGE study. We would like to give special thanks to Wilma M. Akkermans-van Vliet for the DNA isolations and Aino Leegaard Andersen for drafting the first analysis plan.

Conflicts of Interest: The authors declare no conflict of interest. The funders had no role in the design of the study; in the collection, analyses, or interpretation of data; in the writing of the manuscript, or in the decision to publish the results. 


\section{References}

1. United Nations. World Population Ageing 2019 Highlights; UN: New York, NY, USA, 2019. [CrossRef]

2. Crimmins, E.M.; Beltrán-Sánchez, H. Mortality and Morbidity Trends: Is There Compression of Morbidity? J. Gerontol. Ser. B 2010, 66, 75-86. [CrossRef] [PubMed]

3. Harper, S. Economic and social implications of aging societies. Science 2014, 346, 587-591. [CrossRef] [PubMed]

4. Candela, M.; Biagi, E.; Brigidi, P.; O’Toole, P.W.; De Vos, W.M. Maintenance of a healthy trajectory of the intestinal microbiome during aging: A dietary approach. Mech. Ageing Dev. 2014, 137, 70-75. [CrossRef] [PubMed]

5. An, R.; Wilms, E.; Masclee, A.A.M.; Smidt, H.; Zoetendal, E.G.; Jonkers, D. Age-dependent changes in GI physiology and microbiota: Time to reconsider? Gut 2018, 67, 2213-2222. [CrossRef]

6. Biagi, E.; Nylund, L.; Candela, M.; Ostan, R.; Bucci, L.; Pini, E.; Nikkila, J.; Monti, D.; Satokari, R.; Franceschi, C.; et al. Through Ageing, and Beyond: Gut Microbiota and Inflammatory Status in Seniors and Centenarians. PLOS ONE 2010, 5, e10667. [CrossRef]

7. Claesson, M.J.; Cusack, S.; O’Sullivan, O.; Greene-Diniz, R.; De Weerd, H.; Flannery, E.; Marchesi, J.R.; Falush, D.; Dinan, T.G.; Fitzgerald, G.F.; et al. Composition, variability, and temporal stability of the intestinal microbiota of the elderly. Proc. Natl. Acad. Sci. USA 2011, 108, 4586-4591. [CrossRef]

8. Claesson, M.J.; Jeffery, I.B.; Conde, S.; Power, S.E.; O'Connor, E.M.; Cusack, S.; Harris, H.M.B.; Coakley, M.; Lakshminarayanan, B.; O'Sullivan, O.; et al. Gut microbiota composition correlates with diet and health in the elderly. Nature 2012, 488, 178-184. [CrossRef]

9. Cryan, J.F.; Dinan, T.G. Mind-altering microorganisms: The impact of the gut microbiota on brain and behaviour. Nat. Rev. Neurosci. 2012, 13, 701-712. [CrossRef]

10. Hwang, Y.-H.; Park, S.; Paik, J.-W.; Chae, S.-W.; Kim, D.-H.; Jeong, D.-G.; Ha, E.; Kim, M.; Hong, G.; Park, S.-H.; et al. Efficacy and Safety of Lactobacillus Plantarum C29-Fermented Soybean (DW2009) in Individuals with Mild Cognitive Impairment: A 12-Week, Multi-Center, Randomized, Double-Blind, Placebo-Controlled Clinical Trial. Nutrients 2019, 11, 305. [CrossRef]

11. Kim, C.-S.; Cha, L.; Sim, M.; Jung, S.; Chun, W.Y.; Baik, H.W.; Shin, D.-M. Probiotic Supplementation Improves Cognitive Function and Mood with Changes in Gut Microbiota in Community-Dwelling Older Adults: A Randomized, Double-Blind, Placebo-Controlled, Multicenter Trial. J. Gerontol. Ser. A Boil. Sci. Med. Sci. 2020. [CrossRef]

12. Trichopoulou, A.; Lagiou, P. Healthy Traditional Mediterranean Diet: An Expression of Culture, History, and Lifestyle. Nutr. Rev. 2009, 55, 383-389. [CrossRef] [PubMed]

13. Valls-Pedret, C.; Sala-Vila, A.; Serra-Mir, M.; Corella, D.; De La Torre, R.; Martínez-González, M.Á.; Martínez-Lapiscina, E.H.; Fitó, M.; Pérez-Heras, A.; Salas-Salvadó, J.; et al. Mediterranean Diet and Age-Related Cognitive Decline. JAMA Intern. Med. 2015, 175, 1094-1103. [CrossRef] [PubMed]

14. Marseglia, A.; Xu, W.; Fratiglioni, L.; Fabbri, C.; Berendsen, A.A.M.; Bialecka-Debek, A.; Jennings, A.; Gillings, R.; Meunier, N.; Caumon, E.; et al. Effect of the NU-AGE Diet on Cognitive Functioning in Older Adults: A Randomized Controlled Trial. Front. Physiol. 2018, 9, 349. [CrossRef] [PubMed]

15. De Filippis, F.; Pellegrini, N.; Vannini, L.; Jeffery, I.B.; La Storia, A.; Laghi, L.; Serrazanetti, D.I.; Di Cagno, R.; Ferrocino, I.; Lazzi, C.; et al. High-level adherence to a Mediterranean diet beneficially impacts the gut microbiota and associated metabolome. Gut 2015, 65, 1812-1821. [CrossRef] [PubMed]

16. Ghosh, T.S.; Rampelli, S.; Jeffery, I.B.; Santoro, A.; Neto, M.; Capri, M.; Giampieri, E.; Jennings, A.; Candela, M.; Turroni, S.; et al. Mediterranean diet intervention alters the gut microbiome in older people reducing frailty and improving health status: The NU-AGE 1-year dietary intervention across five European countries. Gut 2020, 69, 1218-1228. [CrossRef]

17. Machiels, K.; Joossens, M.; Sabino, J.; De Preter, V.; Arijs, I.; Eeckhaut, V.; Ballet, V.; Claes, K.; Van Immerseel, F.; Verbeke, K.; et al. Faculty Opinions recommendation of A decrease of the butyrate-producing species Roseburia hominis and Faecalibacterium prausnitzii defines dysbiosis in patients with ulcerative colitis. Fac. Opin. Post-Public. Peer Rev. Biomed. Lit. 2015, 63. [CrossRef]

18. Qin, J.; Li, Y.; Cai, Z.; Li, S.; Zhu, J.; Zhang, F.; Liang, S.; Zhang, W.; Guan, Y.; Shen, D.; et al. A metagenome-wide association study of gut microbiota in type 2 diabetes. Nature 2012, 490, 55-60. [CrossRef] 
19. Wang, T.; Cai, G.; Qiu, Y.; Fei, N.; Zhang, M.; Pang, X.; Jia, W.; Cai, S.; Zhao, L. Structural segregation of gut microbiota between colorectal cancer patients and healthy volunteers. ISME J. 2012, 6, 320-329. [CrossRef]

20. Jonaitis, E.M.; Koscik, R.L.; Clark, L.R.; Ma, Y.; Betthauser, T.J.; Berman, S.E.; Allison, S.L.; Mueller, K.D.; Hermann, B.P.; Van Hulle, C.A.; et al. Measuring longitudinal cognition: Individual tests versus composites. Alzheimer's Dement. Diagn. Assess. Dis. Monit. 2018, 11, 74-84. [CrossRef]

21. Santoro, A.; Pini, E.; Scurti, M.; Palmas, G.; Berendsen, A.; Brzozowska, A.; Pietruszka, B.; Szczecinska, A.; Cano, N.; Meunier, N.; et al. Combating inflammaging through a Mediterranean whole diet approach: The NU-AGE project's conceptual framework and design. Mech. Ageing Dev. 2014, 137, 3-13. [CrossRef]

22. Berendsen, A.A.M.; Santoro, A.; Pini, E.; Cevenini, E.; Ostan, R.; Pietruszka, B.; Rolf, K.; Cano, N.J.M.; Caille, A.; Lyon-Belgy, N.; et al. Reprint of: A parallel randomized trial on the effect of a healthful diet on inflammageing and its consequences in European elderly people: Design of the NU-AGE dietary intervention study. Mech. Ageing Dev. 2014, 136, 14-21. [CrossRef] [PubMed]

23. Berendsen, A.M.; Van De Rest, O.; Feskens, E.J.M.; Santoro, A.; Ostan, R.; Pietruszka, B.; Brzozowska, A.; Stelmaszczyk-Kusz, A.; Jennings, A.; Gillings, R.; et al. Changes in Dietary Intake and Adherence to the NU-AGE Diet Following a One-Year Dietary Intervention among European Older Adults-Results of the NU-AGE Randomized Trial. Nutrients 2018, 10, 1905. [CrossRef] [PubMed]

24. Fried, L.P.; Tangen, C.M.; Walston, J.; Newman, A.B.; Hirsch, C.; Gottdiener, J.; Seeman, T.; Tracy, R.; Kop, W.J.; Burke, G.; et al. Frailty in Older Adults: Evidence for a Phenotype. J. Gerontol. Ser. A Boil. Sci. Med. Sci. 2001, 56, M146-M157. [CrossRef] [PubMed]

25. Slimani, N.; Ferrari, P.; Ocké, M.; Welch, A.; Boeing, H.; Van Liere, M.; Pala, V.; Amiano, P.; Lagiou, A.; Mattisson, I.; et al. Standardization of the 24-h diet recall calibration method used in the European Prospective Investigation into Cancer and Nutrition (EPIC): General concepts and preliminary results. Eur. J. Clin. Nutr. 2000, 54, 900-917. [CrossRef]

26. Netherlands Nutrition Centre. Guidelines Wheel of Five; Netherlands Nutrition Centre: The Hague, The Netherlands, 2020. (In Dutch)

27. Ruiz-Ojeda, F.J.; Plaza-Díaz, J.; Sáez-Lara, M.J.; Gil, A. Effects of Sweeteners on the Gut Microbiota: A Review of Experimental Studies and Clinical Trials. Adv. Nutr. 2019, 10, S31-S48. [CrossRef] [PubMed]

28. Salonen, A.; Nikkilä, J.; Jalanka-Tuovinen, J.; Immonen, O.; Rajilić-Stojanović, M.; Kekkonen, R.A.; Palva, A.; De Vos, W.M. Comparative analysis of fecal DNA extraction methods with phylogenetic microarray: Effective recovery of bacterial and archaeal DNA using mechanical cell lysis. J. Microbiol. Methods 2010, 81, 127-134. [CrossRef]

29. Claesson, M.J.; O'Sullivan, O.; Wang, Q.; Nikkilä, J.; Marchesi, J.R.; Smidt, H.; De Vos, W.M.; Ross, R.P.; O'Toole, P.W. Comparative Analysis of Pyrosequencing and a Phylogenetic Microarray for Exploring Microbial Community Structures in the Human Distal Intestine. PLoS ONE 2009, 4, e6669. [CrossRef]

30. Rajilić-Stojanović, M.; Heilig, H.G.H.J.; Molenaar, D.; Kajander, K.; Surakka, A.; Smidt, H.; De Vos, W.M. Development and application of the human intestinal tract chip, a phylogenetic microarray: Analysis of universally conserved phylotypes in the abundant microbiota of young and elderly adults. Environ. Microbiol. 2009, 11, 1736-1751. [CrossRef]

31. Lahti, L.; Elo, L.L.; Aittokallio, T.; Kaski, S. Probabilistic Analysis of Probe Reliability in Differential Gene Expression Studies with Short Oligonucleotide Arrays. IEEE/ACM Trans. Comput. Biol. Bioinform. 2011, 8, 217-225. [CrossRef]

32. Lahti, L.; Torrente, A.; Elo, L.L.; Brazma, A.; Rung, J. A fully scalable online pre-processing algorithm for short oligonucleotide microarray atlases. Nucleic Acids Res. 2013, 41, e110. [CrossRef]

33. Morris, J.C.; Heyman, A.; Mohs, R.C.; Hughes, J.; van Belle, G.; Fillenbaum, G.; Mellits, E.D.; Clark, C. The consortium to establish a registry for Alzheimer's disease (CERAD): I. Clinical and neuropsychological assessment of Alzheimer's disease. Neurology 1989, 39, 1159-1165.

34. Rosen, W.G. Verbal fluency in aging and dementia. J. Clin. Neuropsychol. 1980, 2, 135-146. [CrossRef]

35. Rosen, W.G.; Mohs, R.C.; Davis, K.L. A new rating scale for Alzheimer's disease. Am. J. Psychiatry 1984, 141, 1356-1364. [CrossRef] [PubMed]

36. Babcock, H.; Levy, L. Test and Manual of Directions; The Revised Examination for the Measurement of Efficiency of Mental Functioning; American Psychological Association: Washington, DC, USA, 1940.

37. Reitan, R.M. Validity of the Trail Making Test as an indicator of organic brain damage. Percept. Motor Skills 1958, 8, 271-276. [CrossRef] 
38. Lewis, R.; Kupke, T. (Eds.) The Lafayette Clinic Repeatable Neuropsychological Test Battery: Its Development and Research Applications. In Proceedings of the Annual Meeting of the Southeastern Psychological Association, Hollywood, FL, USA, 4-7 May 1977.

39. Salthouse, T.A.; Babcock, R.L. Decomposing adult age differences in working memory. Dev. Psychol. 1991, $27,763$. [CrossRef]

40. Folstein, M.F.; Folstein, S.E.; McHugh, P.R. "Mini-mental state”. A practical method for grading the cognitive state of patients for the clinician. J. Psychiatr. Res. 1975, 12, 189-198. [CrossRef]

41. Washburn, R.A.; Smith, K.W.; Jette, A.M.; Janney, C.A. The physical activity scale for the elderly (PASE): Development and evaluation. J. Clin. Epidemiol. 1993, 46, 153-162. [CrossRef]

42. R Core Team. R: A Language and Environment for Statistical Computing; R Foundation for Statistical Computing: Vienna, Austria, 2018.

43. Oksanen, J.; Blanchet, F.G.; Kindt, R.; Legendre, P.; Minchin, P.R.; O’Hara, R.B.; Simpson, G.L.; Solymos, P.; Stevens, M.H.H.; Wagner, H. Vegan: Community Ecology Package; R Package Version 2.5-2; R Foundation for Statistical Computing: Vienna, Austria, 2018.

44. Lahti, L.; Shetty, S.; Blake, T.; Salojarvi, J. Microbiome R Package; R Foundation for Statistical Computing: Vienna, Austria, 2017.

45. Revelle, W. Psych: Procedures for Psychological, Psychometric, and Personality Research; Northwestern University: Evanston, IL, USA, 2018.

46. Benjamini, Y.; Hochberg, Y. Controlling the False Discovery Rate: A Practical and Powerful Approach to Multiple Testing. J. R. Stat. Soc. Ser. B Stat. Methodol. 1995, 57, 289-300. [CrossRef]

47. Zhernakova, A.; Kurilshikov, A.; Bonder, M.J.; Tigchelaar, E.F.; Schirmer, M.; Vatanen, T.; Mujagic, Z.; Vila, A.V.; Falony, G.; Vieira-Silva, S.; et al. Population-based metagenomics analysis reveals markers for gut microbiome composition and diversity. Science 2016, 352, 565-569. [CrossRef]

48. Falony, G.; Joossens, M.; Vieira-Silva, S.; Wang, J.; Darzi, Y.; Faust, K.; Kurilshikov, A.; Bonder, M.J.; Valles-Colomer, M.; Vandeputte, D.; et al. Population-level analysis of gut microbiome variation. Science 2016, 352, 560-564. [CrossRef]

49. Partula, V.; Mondot, S.; Torres, M.J.; Kesse-Guyot, E.; Deschasaux, M.; Assmann, K.; Latino-Martel, P.; Buscail, C.; Julia, C.; Galan, P.; et al. Associations between usual diet and gut microbiota composition: Results from the Milieu Intérieur cross-sectional study. Am. J. Clin. Nutr. 2019, 109, 1472-1483. [CrossRef] [PubMed]

50. Shivappa, N.; Steck, S.E.; Hurley, T.G.; Hussey, J.R.; Hébert, J.R. Designing and developing a literature-derived, population-based dietary inflammatory index. Public Health Nutr. 2014, 17, 1689-1696. [CrossRef] [PubMed]

51. Candela, M.; Biagi, E.; Soverini, M.; Consolandi, C.; Quercia, S.; Severgnini, M.; Peano, C.; Turroni, S.; Rampelli, S.; Pozzilli, P.; et al. Modulation of gut microbiota dysbioses in type 2 diabetic patients by macrobiotic Ma-Pi 2 diet. Br. J. Nutr. 2016, 116, 80-93. [CrossRef] [PubMed]

52. Shah, V.; Lambeth, S.M.; Carson, T.; Lowe, J.; Ramaraj, T.; Leff, J.W.; Luo, L.; Bell, C.J. Composition Diversity and Abundance of Gut Microbiome in Prediabetes and Type 2 Diabetes. J. Diabetes Obes. 2015, 2, 108-114. [CrossRef] [PubMed]

53. Karlsson, F.H.; Fåk, F.; Nookaew, I.; Tremaroli, V.; Fagerberg, B.; Petranovic, D.; Bäckhed, F.; Nielsen, J.C. Symptomatic atherosclerosis is associated with an altered gut metagenome. Nat. Commun. 2012, 3, 1245. [CrossRef] [PubMed]

54. Chen, J.; Wright, K.; Davis, J.M.; Jeraldo, P.; Marietta, E.V.; Murray, J.; Nelson, H.; Matteson, E.L.; Taneja, V. An expansion of rare lineage intestinal microbes characterizes rheumatoid arthritis. Genome Med. 2016, 8, 1-14. [CrossRef] [PubMed]

55. Breban, M.; Tap, J.; Leboime, A.; Said-Nahal, R.; Langella, P.; Chiocchia, G.; Furet, J.-P.; Sokol, H. Faecal microbiota study reveals specific dysbiosis in spondyloarthritis. Ann. Rheum. Dis. 2017, 76, 1614-1622. [CrossRef]

56. Zheng, H.; Liang, H.; Wang, Y.; Miao, M.; Shi, T.; Yang, F.; Liu, E.; Yuan, W.; Ji, Z.-S.; Li, D.-K. Altered Gut Microbiota Composition Associated with Eczema in Infants. PLoS ONE 2016, 11, e0166026. [CrossRef]

57. Hall, A.B.; Yassour, M.; Sauk, J.; Garner, A.; Jiang, X.; Arthur, T.; Lagoudas, G.K.; Vatanen, T.; Fornelos, N.; Wilson, R.; et al. A novel Ruminococcus gnavus clade enriched in inflammatory bowel disease patients. Genome Med. 2017, 9, 1-12. [CrossRef] 
58. Henke, M.T.; Kenny, D.J.; Cassilly, C.D.; Vlamakis, H.; Xavier, R.J.; Clardy, J. Ruminococcus gnavus, a member of the human gut microbiome associated with Crohn's disease, produces an inflammatory polysaccharide. Proc. Natl. Acad. Sci. USA 2019, 116, 12672-12677. [CrossRef]

59. Vinolo, M.A.R.; Rodrigues, H.G.; Nachbar, R.T.; Curi, R. Regulation of inflammation by short chain fatty acids. Nutrients 2011, 3, 858-876. [CrossRef] [PubMed]

60. Vieira, E.L.; Leonel, A.J.; Sad, A.P.; Beltrão, N.R.; Costa, T.F.; Ferreira, T.M.; Gomes-Santos, A.C.; Faria, A.M.; Peluzio, M.C.; Cara, D.C.; et al. Oral administration of sodium butyrate attenuates inflammation and mucosal lesion in experimental acute ulcerative colitis. J. Nutr. Biochem. 2012, 23, 430-436. [CrossRef] [PubMed]

61. Vernia, P.; Annese, V.; Bresci, G.; D’Albasio, G.; D’Incà, R.; Giaccari, S.; Ingrosso, M.; Mansi, C.; Riegler, G.; Valpiani, D;; et al. Topical butyrate improves efficacy of 5-ASA in refractory distal ulcerative colitis: Results of a multicentre trial. Eur. J. Clin. Investig. 2003, 33, 244-248. [CrossRef] [PubMed]

62. Sokol, H.; Pigneur, B.; Watterlot, L.; Lakhdari, O.; Bermúdez-Humarán, L.G.; Gratadoux, J.-J.; Blugeon, S.; Bridonneau, C.; Furet, J.-P.; Corthier, G.; et al. Faecalibacterium prausnitzii is an anti-inflammatory commensal bacterium identified by gut microbiota analysis of Crohn disease patients. Proc. Natl. Acad. Sci. USA 2008, 105, 16731-16736. [CrossRef]

63. Prosberg, M.; Bendtsen, F.; Vind, I.; Petersen, A.M.; Gluud, L.L. The association between the gut microbiota and the inflammatory bowel disease activity: A systematic review and meta-analysis. Scand. J. Gastroenterol. 2016, 51, 1407-1415. [CrossRef] [PubMed]

64. Kang, S.; Denman, S.E.; Morrison, M.; Yu, Z.; Dore, J.; Leclerc, M.; McSweeney, C.S. Dysbiosis of fecal microbiota in Crohn's disease patients as revealed by a custom phylogenetic microarray. Inflamm. Bowel Dis. 2010, 16, 2034-2042. [CrossRef] [PubMed]

65. Yassour, M.; Lim, M.Y.; Yun, H.S.; Tickle, T.L.; Sung, J.; Song, Y.-M.; Lee, K.; Franzosa, E.A.; Morgan, X.C.; Gevers, D.; et al. Sub-clinical detection of gut microbial biomarkers of obesity and type 2 diabetes. Genome Med. 2016, 8, 1-14. [CrossRef] [PubMed]

66. Zhang, X.; Shen, D.; Fang, Z.; Jie, Z.; Qiu, X.; Zhang, C.; Chen, Y.; Ji, L. Human Gut Microbiota Changes Reveal the Progression of Glucose Intolerance. PLoS ONE 2013, 8, e71108. [CrossRef]

67. Mbakwa, C.A.; Hermes, G.D.A.; Penders, J.; Savelkoul, P.H.M.; Thijs, C.; Dagnelie, P.C.; Mommers, M.; Zoetendal, E.G.; Smidt, H.; Arts, I.C.W. Gut Microbiota and Body Weight in School-Aged Children: The KOALA Birth Cohort Study. Obesity 2018, 26, 1767-1776. [CrossRef]

68. Depommier, C.; Everard, A.; Druart, C.; Plovier, H.; Van Hul, M.; Vieira-Silva, S.; Falony, G.; Raes, J.; Maiter, D.; Delzenne, N.M.; et al. Supplementation with Akkermansia muciniphila in overweight and obese human volunteers: A proof-of-concept exploratory study. Nat. Med. 2019, 25, 1096-1103. [CrossRef]

69. Canani, R.B. Potential beneficial effects of butyrate in intestinal and extraintestinal diseases. World J. Gastroenterol. 2011, 17, 1519-1528. [CrossRef] [PubMed]

70. Dueñas, M.; Muñoz-González, I.; Cueva, C.; Jiménez-Girón, A.; Sánchez-Patán, F.; Santos-Buelga, C.; Moreno-Arribas, M.V.; Bartolomé, B. A Survey of Modulation of Gut Microbiota by Dietary Polyphenols. BioMed Res. Int. 2015, 2015, 1-15. [CrossRef] [PubMed]

71. Roopchand, D.E.; Carmody, R.N.; Kuhn, P.; Moskal, K.; Rojas-Silva, P.; Turnbaugh, P.J.; Raskin, I. Dietary Polyphenols Promote Growth of the Gut Bacterium Akkermansia muciniphila and Attenuate High-Fat Diet-Induced Metabolic Syndrome. Diabetes 2015, 64, 2847-2858. [CrossRef]

72. Kovatcheva-Datchary, P.; Nilsson, A.C.; Akrami, R.; Lee, Y.S.; De Vadder, F.; Arora, T.; Hallen, A.; Martens, E.; Björck, I.; Bäckhed, F. Dietary Fiber-Induced Improvement in Glucose Metabolism Is Associated with Increased Abundance of Prevotella. Cell Metab. 2015, 22, 971-982. [CrossRef] [PubMed]

73. David, L.A.; Maurice, C.F.; Carmody, R.N.; Gootenberg, D.B.; Button, J.E.; Wolfe, B.E.; Ling, A.V.; Devlin, A.S.; Varma, Y.; Fischbach, M.A.; et al. Diet rapidly and reproducibly alters the human gut microbiome. Nature 2014, 505, 559-563. [CrossRef] [PubMed]

74. Salyers, A.A.; Vercellotti, J.R.; West, S.E.; Wilkins, T.D. Fermentation of mucin and plant polysaccharides by strains of Bacteroides from the human colon. Appl. Environ. Microbiol. 1977, 33, 319-322. [CrossRef] [PubMed]

75. Wexler, H.M.; Daya, S.; Berns, K.I. Bacteroides: The Good, the Bad, and the Nitty-Gritty. Clin. Microbiol. Rev. 2007, 20, 593-621. [CrossRef] 
76. Wu, M.; McNulty, N.P.; Rodionov, D.A.; Khoroshkin, M.S.; Griffin, N.W.; Cheng, J.; Latreille, P.; Kerstetter, R.A.; Terrapon, N.; Henrissat, B.; et al. Genetic determinants of in vivo fitness and diet responsiveness in multiple human gut Bacteroides. Science 2015, 350, aac5992. [CrossRef]

77. De Filippis, F.; Pellegrini, N.; Laghi, L.; Gobbetti, M.; De Filippis, F. Unusual sub-genus associations of faecal Prevotella and Bacteroides with specific dietary patterns. Microbiome 2016, 4, 57. [CrossRef] [PubMed]

78. Larsen, J.M. The immune response to Prevotella bacteria in chronic inflammatory disease. Immunology 2017, 151, 363-374. [CrossRef]

79. Hermes, G.D.A.; Reijnders, D.; Kootte, R.S.; Goossens, G.H.; Smidt, H.; Nieuwdorp, M.; Blaak, E.E.; Zoetendal, E.G. Individual and cohort-specific gut microbiota patterns associated with tissue-specific insulin sensitivity in overweight and obese males. Sci. Rep. 2020, 10, 1-10. [CrossRef] [PubMed]

80. Reichardt, N.; Duncan, S.H.; Young, P.; Belenguer, A.; Leitch, C.M.; Scott, K.P.; Flint, H.J.; Louis, P. Phylogenetic distribution of three pathways for propionate production within the human gut microbiota. ISME J. 2014, 8, 1323-1335. [CrossRef] [PubMed]

81. Hosseini, E.; Grootaert, C.; Verstraete, W.; Van De Wiele, T. Propionate as a health-promoting microbial metabolite in the human gut. Nutr. Rev. 2011, 69, 245-258. [CrossRef] [PubMed]

82. Barbour, J.; Howe, P.R.C.; Buckley, J.D.; Bryan, J.; Coates, A.M. Nut consumption for vascular health and cognitive function. Nutr. Res. Rev. 2014, 27, 131-158. [CrossRef] [PubMed]

83. Devore, E.E.; Kang, J.H.; Breteler, M.M.B.; Grodstein, F. Dietary intakes of berries and flavonoids in relation to cognitive decline. Ann. Neurol. 2012, 72, 135-143. [CrossRef]

84. Kinney, J.W.; Bemiller, S.M.; Murtishaw, A.S.; Leisgang, A.M.; Salazar, A.M.; Lamb, B.T. Inflammation as a central mechanism in Alzheimer's disease. Alzheimer's Dement. Transl. Res. Clin. Interv. 2018, 4, 575-590. [CrossRef]

85. Nguyen, T.L.A.; Vieira-Silva, S.; Liston, A.; Raes, J. How informative is the mouse for human gut microbiota research? Dis. Model. Mech. 2015, 8, 1-16. [CrossRef]

86. Salthouse, T. Major Issues in Cognitive Aging; Oxford University Press: Oxford, UK, 2009; pp. 1-256.

87. Brink, A.C.V.D.; Brouwer-Brolsma, E.M.; Berendsen, A.A.M.; Van De Rest, O. The Mediterranean, Dietary Approaches to Stop Hypertension (DASH), and Mediterranean-DASH Intervention for Neurodegenerative Delay (MIND) Diets Are Associated with Less Cognitive Decline and a Lower Risk of Alzheimer's DiseaseA Review. Adv. Nutr. 2019, 10, 1040-1065. [CrossRef]

88. Li, B.; He, Y.; Ma, J.; Huang, P.; Du, J.; Cao, L.; Wang, Y.; Xiao, Q.; Tang, H.; Chen, S. Mild cognitive impairment has similar alterations as Alzheimer's disease in gut microbiota. Alzheimer's Dement. 2019, 15, 1357-1366. [CrossRef]

89. Kobayashi, Y.; Kuhara, T.; Oki, M.; Xiao, J.-Z. Effects of Bifidobacterium breve A1 on the cognitive function of older adults with memory complaints: A randomised, double-blind, placebo-controlled trial. Benef. Microbes 2019, 10, 511-520. [CrossRef]

90. Akbari, E.; Asemi, Z.; Kakhaki, R.D.; Bahmani, F.; Kouchaki, E.; Tamtaji, O.R.; Hamidi, G.A.; Salami, M. Effect of Probiotic Supplementation on Cognitive Function and Metabolic Status in Alzheimer's Disease: A Randomized, Double-Blind and Controlled Trial. Front. Aging Neurosci. 2016, 8, 256. [CrossRef] [PubMed]

91. Benton, D.; Williams, C.S.; Brown, A.E. Impact of consuming a milk drink containing a probiotic on mood and cognition. Eur. J. Clin. Nutr. 2007, 61, 355-361. [CrossRef] [PubMed]

92. Inoue, T.; Kobayashi, Y.; Mori, N.; Sakagawa, M.; Xiao, J.-Z.; Moritani, T.; Sakane, N.; Nagai, N. Effect of combined bifidobacteria supplementation and resistance training on cognitive function, body composition and bowel habits of healthy elderly subjects. Benef. Microbes 2018, 9, 843-853. [CrossRef] [PubMed] 
93. Mazereeuw, G.; Lanctôt, K.L.; Chau, S.A.; Swardfager, W.; Herrmann, N. Effects of omega-3 fatty acids on cognitive performance: A meta-analysis. Neurobiol. Aging 2012, 33, 1482.e17-1482.e29. [CrossRef]

94. An, R.; Wilms, E.; Smolinska, A.; Hermes, G.D.A.; Masclee, A.; De Vos, P.; Schols, H.; Van Schooten, F.-J.; Smidt, H.; Jonkers, D.; et al. Sugar Beet Pectin Supplementation Did Not Alter Profiles of Fecal Microbiota and Exhaled Breath in Healthy Young Adults and Healthy Elderly. Nutrition 2019, 11, 2193. [CrossRef] [PubMed]

Publisher's Note: MDPI stays neutral with regard to jurisdictional claims in published maps and institutional affiliations.

(C) 2020 by the authors. Licensee MDPI, Basel, Switzerland. This article is an open access article distributed under the terms and conditions of the Creative Commons Attribution (CC BY) license (http://creativecommons.org/licenses/by/4.0/). 